\title{
Efficacy of Trigonella foenum-graecum Seed Extract in Reducing Metabolic and Inflammatory Alterations Associated With Menopause
}

\author{
Mahmood Abedinzade, Sima Nasri, ${ }^{2, *}$ Masome Jamal Omodi, ${ }^{2}$ Elham Ghasemi, ${ }^{2}$ and Ahmad \\ Ghorbani $^{3}$
}

${ }^{1}$ Medical Biotechnology Research Center, Paramedical School, Guilan University of Medical Sciences, Rasht, IR Iran

${ }_{3}^{2}$ Department of Biology, Payame Noor University, Tehran, IR Iran

${ }^{3}$ Pharmacological Research Center of Medicinal Plants, School of Medicine, Mashhad University of Medical Sciences, Mashhad, IR Iran

*Corresponding Author: Sima Nasri, Department of Biology, Payame Noor University, Tehran, IR Iran. Tel: +98-9123277539, Fax: +98-2188948995, E-mail: snasri@yahoo.com

Received 2015 January 4; Revised 2015 April 1; Accepted 2015 April 21.

\begin{abstract}
Background: Several experimental and clinical studies support beneficial effects of Trigonella foenum-graecum (fenugreek) in the management of metabolic diseases and inflammatory disorders.

Objectives: The purpose of this study was to examine the effect of T. foenum-graecum seed extract in reducing the metabolic and inflammatory alternations associated with menopause.

Materials and Methods: In this experimental study, 49 rats were divided into seven groups:(I) sham-control,(II) ovariectomized-control, (III and IV) ovariectomized treated with 50 and $150 \mathrm{mg} / \mathrm{kg}$ of T. foenum-graecum seed ethanolic extract, (V and VI) ovariectomized treated with 50 and $150 \mathrm{mg} / \mathrm{kg}$ of T. foenum-graecum hexanic extract, (VII) ovariectomized-positive control treated with $10 \mu \mathrm{g} / \mathrm{kg}$ of estradiol. The extracts were injected intraperitoneally one day after ovariectomy and the treatments were lasted for 42 days.

Results: Fasting blood glucose and body weight gain increased significantly in the ovariectomized-control group compared with that in the sham animals $(\mathrm{P}<0.05)$. Administration of estradiol and T. foenum-graecum (50 and $150 \mathrm{mg} / \mathrm{dL}$ of hexanic extract and $150 \mathrm{mg} / \mathrm{kg}$ of ethanolic extract) significantly diminished the increase in glucose and body weight $(\mathrm{P}<0.05)$. The serum level of interleukin-1 (IL-1), interleukin-6 (IL-6), and tumor necrosis factor- $\alpha$ (TNF- $\alpha$ ) in the ovariectomized control group was significantly higher than those in the sham animals $(\mathrm{P}<0.05)$. Both hexanic and ethanolic extracts as well as estradiol were able to decrease level of these cytokines in the serum of ovariectomized rats $(\mathrm{P}<0.05)$.

Conclusions: The results of the present study show that administration of T. foenum-graecum corrects metabolic and inflammatory alterations associated with ovariectomy and has a potential for the management of menopause.
\end{abstract}

Keywords: Cytokines, Menopause, Rats, Trigonella foenum-graecum

\section{Background}

Menopause is associated with increased risk of metabolic diseases such as type 2 diabetes and metabolic syndrome (1,2). Dyslipidemia, obesity, and insulin resistance are of the most common features of the metabolic syndrome in menopausal woman and known to be important risk factors for cardiovascular diseases (3-5). Menopause is also associated with a wide range of changes in the expression and secretion of proinflammatory cytokines which may explain increased incidence of osteoporosis, Alzheimer, arthritis, and other inflammatory diseases seen in a postmenopausal period (6-9).

For many years, hormone therapy was the first primary treatment modality for the management of menopause; however, it had own limitations like increasing risk of stroke, coronary heart disease, pulmonary embolism, and ovarian cancer $(1,10)$. Therefore, development of new agents with anti-inflammatory action and lesser side effects for management of menopause remains an attractive subject. It has been reported that a number of me- dicinal plants may be useful for preventing or treating some menopausal related complications such as insulin resistance, dyslipidemia, hepatic steatosis, weight gain, inflammation, and loss of bone mass (11-13).

Trigonella foenum-graecum (fenugreek), a plant of Fabaceae family, has a long history for management of diabetes and dyslipidemia $(14,15)$. Several studies also support anti-inflammatory and immunomodulatory activities of $T$. foenum-graecum in adult male animals (1618). Recently, Sindhu et al. (19) reported that mucilage extracted from ethanolic extract (EE) of T. foenum graecum has anti-inflammatory and antioxidative properties on adjuvant-induced arthritis in female rats. Further, Hakimi et al. showed that T. foenum graecum seed decreases the number of hot flashes and vasomotor symptoms in menopausal women (20). However, to the best of our knowledge, no study has yet evaluated the effect of this plant on the level of proinflammatory cytokines in menopause.

Copyright (C) 2015, Iranian Red Crescent Medical Journal. This is an open-access article distributed under the terms of the Creative Commons Attribution-NonCommercial 4.0 International License (http://creativecommons.org/licenses/by-nc/4.0/) which permits copy and redistribute the material just in noncommercial usages, provided the original work is properly cited. 
Abedinzade M et al.

\section{Objectives}

The present work was performed to investigate the effects of chronic treatment with $T$. foenum graecum seed extracts on serum concentration of interleukin-1 (IL-1), interleukin-6 (IL-6) and tumor necrosis factor- $\alpha$ (TNF- $\alpha$ ) in ovariectomized rats.

\section{Materials and Methods}

\subsection{Plant Material and Extraction}

The seeds of T. foenum-graecum were purchased from local market (Guilan, Iran) and identified at the herbarium of Agricultural Research Center of Guilan University (Iran). The EE and Hexanic Extract (HE) of T. foenumgraecum were prepared using a maceration method as described previously $(21,22)$. Briefly, the air-dried powder of the seeds was suspended in $96 \%$ ethanol ( $5 \mathrm{~mL}$ per $\mathrm{g}$ of seed) and maintained for 72 hour at $37^{\circ} \mathrm{C}$. Then the solvent was removed and a new extraction started again with fresh ethanol. This step was repeated once more to get the best extraction efficiency. Finally, the EE was filtered through Whatman No.1 filter paper and dried using a rotary vacuum evaporator (GLF, Germany) at $50^{\circ} \mathrm{C}$. The $\mathrm{HE}$ was prepared with the same procedure as for the EE.

\subsection{Animals}

Female Wistar rats initially weighing 190 to 220 g were obtained from Pasteur Institute, Hesarak Branch, Iran. The animals were maintained at $22^{\circ} \mathrm{C} \pm 4^{\circ} \mathrm{C}$ on a light/ dark cycle of 12 hour and away from stress. At all stages of the study, they had free access to enough laboratory chow and tap water ad libitum. Ethical rules of working with laboratory animals were approved by Guilan University of Medical Sciences.

\subsection{Experimental Design}

This work was an experimental study. After two weeks acclimatization period, animals were randomly divided into the following 7 experimental groups, each group including 7 animals: group I included sham control rats; group II comprised ovariectomized control animals; groups III and IV included ovariectomized animals and administrated intraperitoneally EE of T. foenum-graecum (50 and $150 \mathrm{mg} / \mathrm{kg}$, respectively); groups V and VI comprised ovariectomized animals and treated intraperitoneally HE of $T$. foenum-graecum (50 and $150 \mathrm{mg} / \mathrm{kg}$, respectively); groups VII included ovariectomized positive control rats, which administrated orally $10 \mu \mathrm{g} / \mathrm{kg}$ of $17-\beta$ estradiol valerate (Aburaihan Pharmaceutical Co., Iran). The treatments were started one day after removal of ovaries and lasted for 42 days. During this period, animals in the sham control and ovariectomized control groups received saline as a vehicle. Fasting Blood Glucose (FBG) and body weight of all of the rats were recorded prior to the start and at the end of treatments.

\subsection{Ovariectomy Surgery}

After an overnight fast, each rat was anesthetized with intraperitoneally injection of $320 \mathrm{mg} / \mathrm{kg}$ chloralhydrate (Arya Pharmaceutical Co., Iran) (23). Then, a small abdominal skin incision was performed and after exposing ovaries, they were removed bilaterally and tubal ends were closed using 2/0 silk string to prevent internal bleeding. Then the fat pad was repositioned into the abdomen and muscle and skin were connected by $2 / 0$ chromic catgut sutures in two layers. The animal was placed in a warm place to come intellect. The animals in the control group underwent a similar procedure without eliminating the ovaries.

\subsection{Biochemical Assays}

At the end of the 42th day, blood sample was collected from tail vein of fasted animals for biochemical assays. The samples were centrifuged for 5 minutes at $3000 \mathrm{rpm}$ and supernatants were maintained at $-20^{\circ} \mathrm{C}$ for further analysis. The level of FBG was determined using Accucheck glucometer (Roche Diagnostic, Germany). Concentrations of IL-1, IL- 6 and TNF- $\alpha$ were measured by E0071Ra, E90079Ra, and E90133Ra Elisa kit, respectively (Life Science Inc, China).

\subsection{Statistical Analysis}

Differences between means of different groups were analyzed using one-way analysis of variance (ANOVA) followed by Tukey's post hoc test for multiple comparisons. Paired t-test was used to compare the differences between day 0 and day 42 . The P-values less than 0.05 were considered to be statistically significant. Results were exhibited as the Mean \pm Standard Error of the Mean (SEM).

\section{Results}

\subsection{Effects of T. foenum-graecum on Blood Glucose and Body Weight}

In nonovariectomized sham group, the mean FBG on day $0(5.72 \pm 0.12 \mathrm{mmol} / \mathrm{L})$ and day $42(5.38 \pm 0.11 \mathrm{mmol} / \mathrm{L})$ was not significantly different. On the other hand, concentration of FBG at the end of the study was significantly higher than day 0 in ovariectomized control animals (6.16 $\pm 0.13 \mathrm{mmol} / \mathrm{L}$ vs. $8.77 \pm 0.47 \mathrm{mmol} / \mathrm{L}, \mathrm{P}<0.05)$. Although the administration of estradiol or T. foenum-graecum (50 and $150 \mathrm{mg} / \mathrm{dl}$ of $\mathrm{HE}$ and $150 \mathrm{mg} / \mathrm{kg}$ of $\mathrm{EE}$ ) to ovariectomized animals significantly diminished $(\mathrm{P}<0.05)$ the increase of FBG, in all treated groups the level of FBG was still higher than that of day 0 (Table 1 ).

There was a significant difference regarding weight gain between the sham control ( $53 \pm 9 \mathrm{~g})$ and ovariectomized control groups ( $111 \pm 7 \mathrm{~g}, \mathrm{P}<0.05)$. Estradiol and both extracts of $T$. foenum-graecum significantly decreased the body-weight gain compared to the ovariectomized control group $(\mathrm{P}<0.05)$. 
Abedinzade M et al.

Table 1. Effects of Trigonella foenum-graecum on Body Weight and Fasting Blood Glucose of Ovariectomized Rats ${ }^{\mathrm{a}, \mathrm{b}}$

\begin{tabular}{|c|c|c|c|}
\hline \multirow[t]{2}{*}{ Animal Groups } & \multicolumn{2}{|c|}{ Blood Glucose, $\mathrm{mmol} / \mathrm{L}$} & \multirow{2}{*}{$\begin{array}{l}\text { Weight Gain During } 42 \\
\text { days, } \mathrm{g}\end{array}$} \\
\hline & Day 0 & Day 42 & \\
\hline Control & $5.72 \pm 0.12$ & $5.38 \pm 0.11$ & $53 \pm 9^{C}$ \\
\hline OVA + Saline & $6.16 \pm 0.13$ & $8.77 \pm 0.47$ & $111 \pm 7$ \\
\hline OVA + Estradiol & $5.88 \pm 0.14$ & $7.44 \pm 0.32$ & $58 \pm 6^{C}$ \\
\hline OVA + HE $50 \mathrm{mg} / \mathrm{kg}$ & $5.22 \pm 0.13$ & $7.33 \pm 0.16^{c, d}$ & $66 \pm 8^{C}$ \\
\hline OVA + HE $150 \mathrm{mg} / \mathrm{kg}$ & $5.5 \pm 0.13$ & $7.11 \pm 0.18^{\mathrm{c}, \mathrm{d}}$ & $64 \pm 7^{c}$ \\
\hline OVA + EE 50 mg/kg & $5.61 \pm 0.14$ & $7.5 \pm 0.15^{\mathrm{d}}$ & $81 \pm 8^{\mathrm{d}}$ \\
\hline OVA + EE $150 \mathrm{mg} / \mathrm{kg}$ & $4.94 \pm 0.13^{d}$ & $7.16 \pm 0.15^{\mathrm{c}, \mathrm{d}}$ & $74 \pm 9^{c}$ \\
\hline
\end{tabular}

a Abbreviations: EE, ethanolic extract; HE, hexanic extract; and OVA, ovariectomy.

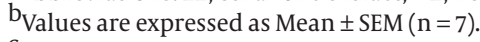

${ }^{\mathrm{C}} \mathrm{P}<0.05 \mathrm{vs}$. OVA + Saline.

$\mathrm{d}_{\mathrm{P}}<0.05$ vs. Day 0 at the corresponding group.

Figure 1. Effect of Trigonella foenum-graecum on Concentration of

Interlukin-1 in Blood of the Ovariectomized Rats

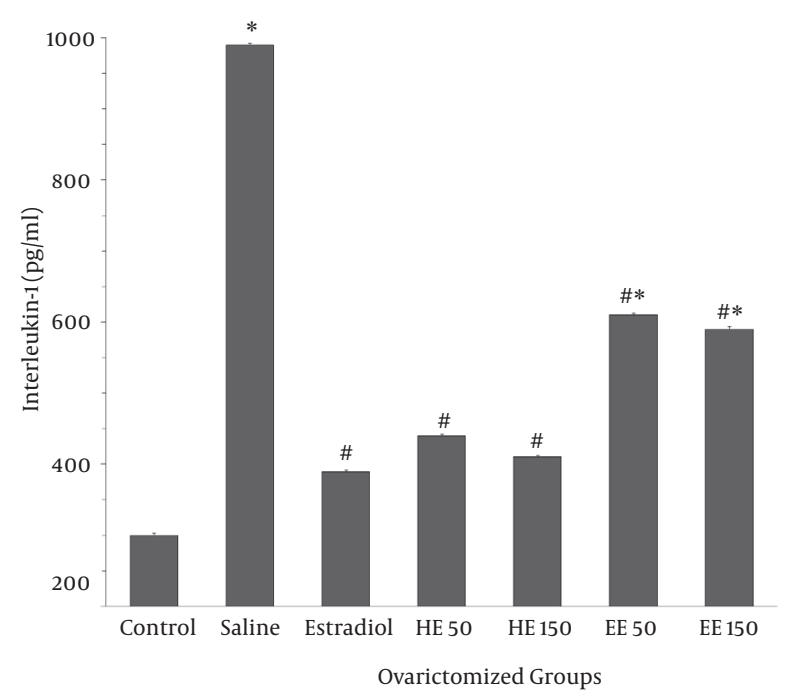

The animals were subjected to ovariectomy surgery and then treated intraperitoneally with $10 \mu \mathrm{g} / \mathrm{kg}$ estradiol or concentrations of $50 \mathrm{mg} / \mathrm{kg}$ and $150 \mathrm{mg} / \mathrm{kg}$ of HE and EE of T. foenum-graecum seeds for 6 weeks. Values are expressed as Mean \pm SEM $(n=7)$. ${ }^{*} \mathrm{P}<0.05$ vs. control group; $\# \mathrm{P}<0.05$ vs. saline group.

\subsection{Effects of T. foenum-graecum on Proinflamma- toryCytokines}

As shown in Figure 1, the serum IL-1 level of the saline-injected rats in the ovariectomized group was significantly higher than those of the sham animals ( $990 \pm 2.9$ vs. 300 $\pm 2.8 \mathrm{pg} / \mathrm{mL}, \mathrm{P}<0.05)$. Administration of both HE and EE of T. foenum-graecum significantly decreased serum IL-1 in the ovariectomized rats compared to the saline group ( $\mathrm{P}<0.05)$. The level of IL-1 in groups received 50 and $150 \mathrm{mg} / \mathrm{kg}$ of HE was $440 \pm 2.8 \mathrm{pg} / \mathrm{mL}$ and $410 \pm 2.2 \mathrm{pg} /$ $\mathrm{mL}$, respectively. Also, concentrations of IL-1 in animals treated with 50 and $150 \mathrm{mg} / \mathrm{kg}$ of EE were $410 \pm 2.2 \mathrm{pg} /$ $\mathrm{mL}$ and $610 \pm 2.7 \mathrm{pg} / \mathrm{mL}$, respectively. The effect of HE was
Figure 2. Effect of Trigonella foenum-graecum on Concentration of Interlukin-6 in Blood of Ovariectomized Rats

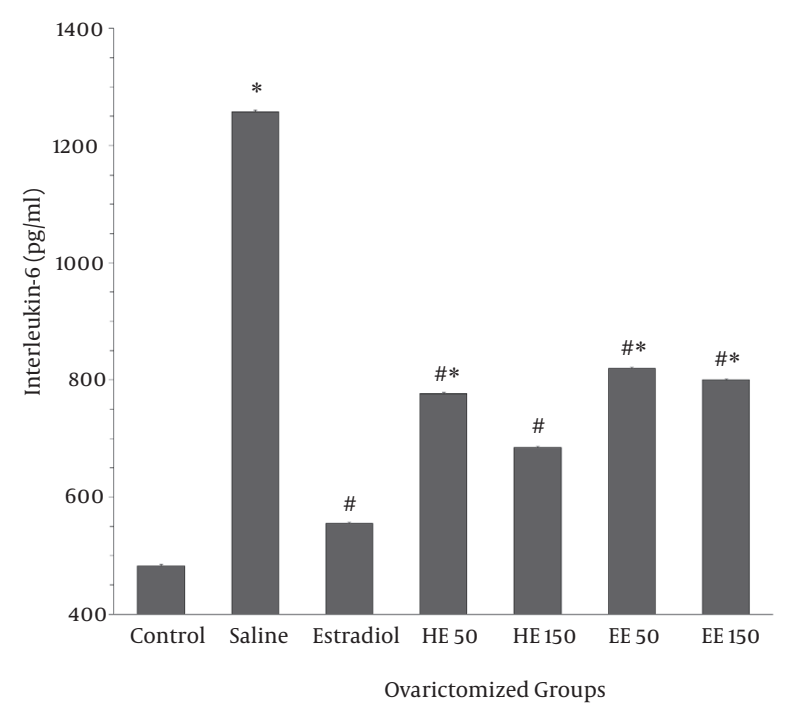

The animals were subjected to ovariectomy surgery and then treated intraperitoneally with $10 \mu \mathrm{g} / \mathrm{kg}$ estradiol or concentrations of $50 \mathrm{mg} / \mathrm{kg}$ and $150 \mathrm{mg} / \mathrm{kg}$ ofHE and EE of T. foenum-graecum seeds for 6 weeks. Values are expressed as Mean $\pm \operatorname{SEM}(n=7)$. ${ }^{*} \mathrm{P}<0.05$ vs. control group; $\# \mathrm{P}<0.05$ vs. saline group.

comparable to that of induced by $10 \mu \mathrm{g} / \mathrm{kg}$ of estradiol $(389 \pm 2.9 \mathrm{pg} / \mathrm{mL})$.

Similarly, serum IL-6 significantly increased in ovariectomized control group when compared to the sham animals $(1258 \pm 2.7$ vs. $483 \pm 3 \mathrm{pg} / \mathrm{mL}, \mathrm{P}<0.05)$. As shown in Figure 2, hexanic and ethanolic extracts of $T$. foenum-graecum, like estradiol, diminished the IL-6 level in ovariectomized animals ( $\mathrm{P}<0.05$ as compared with saline group). Treatment with 50 and $150 \mathrm{mg} / \mathrm{kg}$ of HE was also able to significantly decrease serum TNF- $\alpha$ from $999 \pm 2.4 \mathrm{pg} / \mathrm{mL}$ (saline group) to $457 \pm 2.5$ and $445 \pm 2.6 \mathrm{pg} / \mathrm{mL}$, respectively, comparable to the effect of estradiol $(430 \pm 2.6 \mathrm{pg} / \mathrm{mL})$. A similar decrease in TNF- $\alpha$ concentration was induced by both doses of EE (Figure 3). 
Abedinzade M et al.

Figure 3. Effect of Trigonella foenum-graecum on Concentration of Tumor Necrosis Factor- $\alpha$ in Blood of Ovariectomized Rats

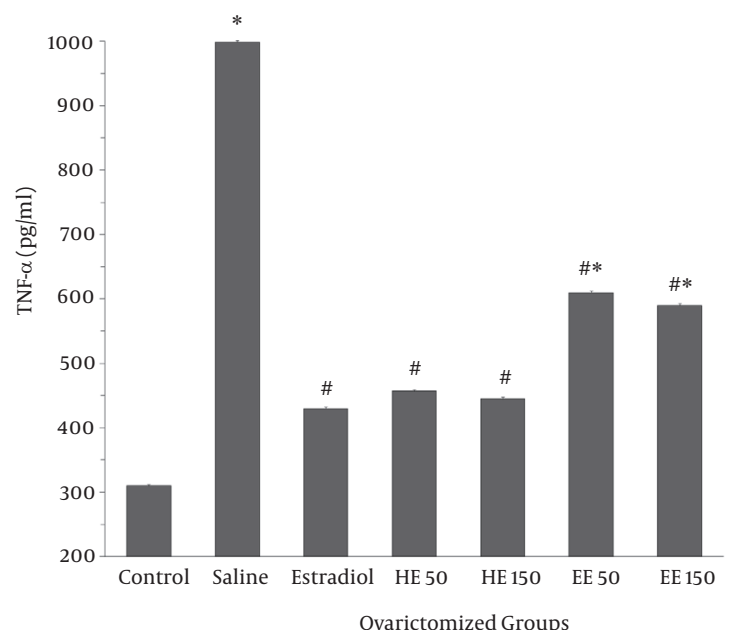

The animals were subjected to ovariectomy surgery and then treated in traperitoneally with $10 \mu \mathrm{g} / \mathrm{kg}$ estradiol or concentrations of $50 \mathrm{mg} / \mathrm{kg}$ and $150 \mathrm{mg} / \mathrm{kg}$ of HE and EE of T. foenum-graecum seeds for 6 weeks. Values are expressed as Mean \pm SEM $(n=7)$. ${ }^{*} \mathrm{P}<0.05$ vs. control group; \# $\mathrm{P}<0.05$ vs. saline group.

\section{Discussion}

The prevalence of metabolic syndrome and inflammatory diseases increases during menopause with the overproduction of proinflammatory cytokines. The present study showed that both HE and EE of T. foenumgraecum seed are able to improve metabolic status and decrease level of these cytokines in ovariectomized rats. Ovariectomy is a standard experimental model of menopause in rodent to investigate pharmacological management of postmenopausal symptoms (11, 12, 24, $25)$. In our study, in agreement with previous reports, ovariectomy led to increased body weight gain (25, 26). This increase of body weight was accompanied by a significant raise of blood glucose. Administration of estradiol could diminish the increase of both body weight and FBG. Similarly, Abbas and Elsamanoudy observed that estradiol decreases FBG, fasting insulin, and Homeostatis Model Assessment of Insulin Resistance (HOMA-IR, a predictor of insulin sensitivity) in ovariectomized rats (24). The beneficial effects of estradiol on glucose homeostasis and body weight were mimicked by $T$. foenum-graecum. Hypoglycemic effect of T. foenumgraecum has been demonstrated previously in several experimental and clinical studies (27). This effect may be achieved by inhibition of intestinal glucose absorption, enhancing insulin actions on tissues, and activation of hepatic enzymes $(28,29)$. The inhibitory effect of $T$. foenum-graecum on weight gain of ovariectomized rats may be related to improvement of insulin resistance. This is in consistent with previous reports that $T$. foenum-graecum reduces the body weight gain and hyperlipidaemia induced by high-fat $\operatorname{diet}(30,31)$.

As reported by other researchers, in our study ovariectomy led to increased level of proinflammatory cytokines. The mechanism underlying elevated inflammation markers in postmenopausal period is not exactly clear; however, excess production of cytokines by fat and bone marrow can be involved $(4,32)$. The cytokines TNF- $\alpha$, IL-1, and IL- 6 have obtained the most attention due to their prominent causal role in postmenopausal inflammatory diseases $(7,33)$. In this work, estradiol replacement could restore the level of these cytokines to near that of control animals. The mechanisms by which estrogen modulates the level and activity of cytokines may include alterations of immune cell function, antioxidative actions, and changes in nitric oxide activity $(6,32,33)$. Similar mechanisms may describe an inhibitory effect of T. foenumgraecum on the level of TNF- $\alpha$, IL-1, and IL- 6 . It has been reported that this plant has estrogenic activities in vitro (34). The presence of phytoestrogen compounds like diosgenin in T. foenum-graecum may be responsible for this estrogenic effect (35). On the other hand, several studies have shown that $T$. foenum-graecum has antioxidative, anti-inflammatory, and immunomodulatory activities in male and female animals (16-19). For example, it was demonstrated that diosgenin induces anti-inflammatory action in adipose tissue (36). Sindhu et al. reported that EE of T. foenum graecum decreases the blood levels of IL-1, IL-2, IL-6, and TNF- $\alpha$ in female rat model of arthritis (19) Also, treatment with hydroalcoholic extract of $T$. foenum graecum seed reduces oxidative stress and the proinflammatory cytokines TNF- $\alpha$ and IL-6 in diabetic rats (37). Further, it has been reported that improvement in glucose metabolism with weight loss is independently associated with reduction of cytokine levels (38).

In this study, we used EE and HE of T. foenum-graecum to test beneficial effects of this plant in the management of metabolic and inflammatory alterations associated with menopause. For extraction of plant materials, the solvents are chosen based on their selectivity for the compounds to be extracted. Nonpolar solvent such as hexane is used to extract lipophilic constituents (e.g. fatty acids, alkanes, sterols, coumarins, and some terpenoids). Solvents with medium-polarity such as ethyl acetate are used to extract constituents with intermediate polarity (e.g. flavonoids and some alkaloids). A more polar solvent such as ethanol is used to extract more polar constituents (e.g. tannins and glycosides) (39, 40). Interestingly, in our experiment, both EE and HE of T. foenum-graecum could correct metabolic and inflammatory alterations induced by ovariectomy (although the HE showed stronger effects). Therefore, it can be concluded that both polar and nonpolar constituents of $T$. foenum-graecum are involved in the beneficial effects of this plant. Diosgenin, a steroid saponin with anti-inflammatory, antioxidative, and estrogenic properties, may be of the candidate constituents responsible for the above-mentioned effects of 
T. foenum-graecum $(31,35,36)$. Further works on isolation and characterization of active compound of the plant would be of interest.

This study described observations on the effect of T. foenum-graecum on metabolic and inflammatory alterations in a rat model of menopause, which may not mimic human menopause. Therefore, well-planned clinical studies on this topic are needed. Another limitation of the present work is the failure to address exact compound responsible for the effects of $T$. foenum-graecum. Also, long-term safety and potential adverse effects of T. foenum-graecum in menopause women should be well-defined.

In conclusion, the present study showed that the administration of $T$. foenum-graecum improves metabolic features, and corrects inflammatory alterations associated with ovariectomy and thus has a potential for management of menopause.

\section{Acknowledgments}

We would like to highly appreciate the kind cooperation of Dr. Babaei.

\section{Footnotes}

Authors' Contribution:Mahmood Abedinzade and Sima Nasri designed the study and collected data. Masome Jamal Omodi and Elham Ghasemi collected data. Ahmad Ghorbani performed the statistical analysis, managed the literature searches and wrote the first draft of the manuscript. All authors read and approved the final version of the manuscript.

Funding/Support:This work was financially supported by Guilan University of Medical Sciences, Rasht, IR Iran.

\section{References}

1. Bulun SE. Physiology and Pathology of the Female Reproductive Axis. In: Melmed S, Polonsky KS, Larsen PR, editors. Williams textbook of endocrinology. Philadelphia: Elsevier; 2011. pp. 581-660.

2. Carr MC. The emergence of the metabolic syndrome with menopause. J Clin Endocrinol Metab. 2003;88(6):2404-11. doi: 10.1210/ jc.2003-030242. [PubMed: 12788835]

3. Gaspard U. Hyperinsulinaemia, a key factor of the metabolic syndrome in postmenopausal women. Maturitas. 2009;62(4):3625. doi:10.1016/j.maturitas.2008.11.026. [PubMed: 19131194]

4. Sites CK, Toth MJ, Cushman M, L'Hommedieu GD, Tchernof A Tracy RP, et al. Menopause-related differences in inflammation markers and their relationship to body fat distribution and insulin-stimulated glucose disposal. Fertility and Sterility. 2002;77(1):128-35. [PubMed: 11779602]

5. Rosano GM, Vitale C, Marazzi G, Volterrani M. Menopause and cardiovascular disease: the evidence. Climacteric. 2007;10 Suppl 1:19-24. doi: 10.1080/13697130601114917. [PubMed: 17364594]

6. Pacifici R, Brown C, Puscheck E, Friedrich E, Slatopolsky E, Maggio D, et al. Effect of surgical menopause and estrogen replacement on cytokine release from human blood mononuclear cells. Proc Natl Acad Sci U S A. 1991;88(12):5134-8. [PubMed: 2052592]

7. Pacifici R. Estrogen, cytokines, and pathogenesis of postmenopausal osteoporosis. J Bone Miner Res. 1996;11(8):1043-51. doi: 10.1002/jbmr.5650110802. [PubMed: 8854239]

8. Paganini-Hill A, Henderson VW. Estrogen deficiency and risk of Alzheimer's disease in women. Am J Epidemiol.1994;140(3):256-61. [PubMed: 8030628]
9. Wluka AE, Cicuttini FM, Spector TD. Menopause, oestrogens and arthritis. Maturitas. 2000;35(3):183-99. [PubMed:10936736]

10. Farrell E. Medical choices available for management of menopause. Best Pract Res Clin Endocrinol Metab. 2003;17(1):1-16. [PubMed:12763509]

11. Kim MJ, Park JH, Kwon DY, Yang HJ, Kim da S, Kang S, et al. The supplementation of Korean mistletoe water extracts reduces hot flushes, dyslipidemia, hepatic steatosis, and muscle loss in ovariectomized rats. Exp Biol Med (Maywood). 2015;240(4):47787. doi: 10.1177/1535370214551693. [PubMed: 25258426]

12. Kaume L, Gilbert WC, Brownmiller C, Howard LR, Devareddy L. Cyanidin 3-O- $\beta$-d-glucoside-rich blackberries modulate hepatic gene expression, and anti-obesity effects in ovariectomized rats. Journal of Functional Foods. 2012;4(2):480-8.

13. Prasannarong M, Saengsirisuwan V, Piyachaturawat P, Suksamrarn A. Improvements of insulin resistance in ovariectomized rats by a novel phytoestrogen from Curcuma comosa Roxb. BMC Complement Altern Med. 2012;12:28. doi: 10.1186/1472-6882-12-28. [PubMed: 22463706]

14. Ghorbani A, Hadjzadeh MA, Rajaei Z, Zendehbad SB. Effects of fenugreek seeds on adipogenesis and lipolysis in normal and diabetic rats. PakJ Biol Sci. 2014;17(4):523-8. [PubMed: 25911840]

15. Ghorbani A. Phytotherapy for diabetic dyslipidemia: evidence from clinical trials. Clinical Lipidology. 2013;8(3):311-9.

16. Bin-Hafeez B, Haque R, Parvez S, Pandey S, Sayeed I, Raisuddin S. Immunomodulatory effects of fenugreek (Trigonella foenum graecum L.) extract in mice. Int Immunopharmacol. 2003;3(2):257-65. doi:10.1016/S1567-5769(02)00292-8. [PubMed: 12586606]

17. Vyas S, Agrawal RP, Solanki P, Trivedi P. Analgesic and anti-inflammatory activities of Trigonella foenum-graecum (seed) extract. Acta Pol Pharm. 2008;65(4):473-6. [PubMed:19051589]

18. Mandegary A, Pournamdari M, Sharififar F, Pournourmohammadi S, Fardiar R, Shooli S. Alkaloid and flavonoid rich fractions of fenugreek seeds (Trigonella foenum-graecum L.) with antinociceptive and anti-inflammatory effects. Food Chem Toxicol. 2012;50(7):2503-7. doi: 10.1016/j.fct.2012.04.020. [PubMed: 22542922]

19. Sindhu G, Ratheesh M, Shyni GL, Nambisan B, Helen A. Anti-inflammatory and antioxidative effects of mucilage of Trigonella foenum graecum (Fenugreek) on adjuvant induced arthritic rats. Int Immunopharmacol. 2012;12(1):205-11. doi: 10.1016/j.intimp.2011.11.012. [PubMed: 22155102]

20. Hakimi S, Mohammad Alizadeh S, Delazar A, Abbasalizadeh F, Bamdad Mogaddam R, Siiahi MR, et al. Probable effects of fenugreek seed on hot flash in menopausal women. Journal of Medicinal Plants. 2006;3(19):9-14

21. Nasri S, Abedinzade M, Jamal Omidi M, Noursabaghi F. Comparison of Analgesic and Hypoglycemic Effect of Hexanic and Alcohlic Extract of Fenugreek Seed in Male Diabetic Rats. Journal of Ardabil University of Medical Sciences. 2013;13(1):102-9.

22. Shafiee-Nick R, Ghorbani A, Vafaee Bagheri F, Rakhshandeh H. Chronic administration of a combination of six herbs inhibits the progression of hyperglycemia and decreases serum lipids and aspartate amino transferase activity in diabetic rats. Adv Pharmacol Sci. 2012;2012:789796. doi: 10.1155/2012/789796. [PubMed: 23304131]

23. Field KJ, White WJ, Lang CM. Anaesthetic effects of chloral hydrate, pentobarbitone and urethane in adult male rats. Lab Anim. 1993;27(3):258-69. [PubMed: 8366672]

24. Abbas AM, Elsamanoudy AZ. Effects of 17beta-estradiol and antioxidant administration on oxidative stress and insulin resistance in ovariectomized rats. Can J Physiol Pharmacol. 2011;89(7):497-504. doi:10.1139/Y11-053. [PubMed: 21812527]

25. Ryou SH, Kang MS, Kim KI, Kang YH, Kang JS. Effects of green tea or Sasa quelpaertensis bamboo leaves on plasma and liver lipids, erythrocyte Na efflux, and platelet aggregation in ovariectomized rats. Nutr Res Pract. 2012;6(2):106-12. doi: 10.4162| nrp.2012.6.2.106. [PubMed: 22586498]

26. Cheng PY, Lee YM, Yen MH, PengJC, Lam KK. Reciprocal effects of alpha-lipoic acid on adenosine monophosphate-activated protein kinase activity in obesity induced by ovariectomy in rats. Menopause. 2011;18(9):1010-7. doi: 10.1097/gme.0b013e31820db576. 
[PubMed: 21505371]

27. Ghorbani A. Best herbs for managing diabetes: a review of clinical studies. Brazilian Journal of Pharmaceutical Sciences. 2013;49(3):413-22.

28. Vijayakumar MV, Bhat MK. Hypoglycemic effect of a novel dialysed fenugreek seeds extract is sustainable and is mediated, in part, by the activation of hepatic enzymes. Phytother Res. 2008;22(4):500-5. doi: 10.1002/ptr.2351. [PubMed:18338783]

29. Hannan JM, Ali L, Rokeya B, Khaleque J, Akhter M, Flatt PR, et al. Soluble dietary fibre fraction of Trigonella foenum-graecum (fenugreek) seed improves glucose homeostasis in animal models of type 1 and type 2 diabetes by delaying carbohydrate digestion and absorption, and enhancing insulin action. Br J Nutr. 2007;97(3):514-21. doi: 10.1017/S0007114507657869. [PubMed: 17313713]

30. Handa T, Yamaguchi K, Sono Y, Yazawa K. Effects of fenugreek seed extract in obese mice fed a high-fat diet. Biosci Biotechnol Biochem. 2005;69(6):1186-8. doi: 10.1271/bbb.69.1186. [PubMed: 15973051]

31. Al-Matubsi HY, Nasrat NA, Oriquat GA, Abu-Samak M, Al-Mzain KA, Salim M. The hypocholesterolemic and antioxidative effect of dietary diosgenin and chromium chloride supplementation on high-cholesterol fed Japanese quails. Pak J Biol Sci. 2011;14(7):425-32. [PubMed: 21902054]

32. Bismar H, Diel I, Ziegler R, Pfeilschifter J. Increased cytokine secretion by human bone marrow cells after menopause or discontinuation of estrogen replacement. J Clin Endocrinol Metab. 1995;80(11):3351-5. doi: 10.1210/jcem.80.11.7593450. [PubMed: 7593450]

33. Pfeilschifter J, Koditz R, Pfohl M, Schatz H. Changes in proin- flammatory cytokine activity after menopause. Endocr Rev. 2002;23(1):90-119. doi:10.1210/edrv.23.1.0456. [PubMed:11844745]

34. Sreeja S, Anju VS, Sreeja S. In vitro estrogenic activities of fenugreek Trigonella foenum graecum seeds. Indian J Med Res. 2010;131:814-9. [PubMed: 20571172]

35. Raju J, Rao CV. Diosgenin, a steroid saponin constituent of yams and fenugreek: emerging evidence for applications in medicine. In: Rasooli I, editor. Bioactive Compounds in Phytomedicine. Croatia: InTech; 2011. p. 125.

36. Uemura T, Hirai S, Mizoguchi N, Goto T, Lee JY, Taketani K, et al. Diosgenin present in fenugreek improves glucose metabolism by promoting adipocyte differentiation and in hibiting inflammation in adipose tissues. Mol Nutr Food Res 2010;54(11):1596-608. doi:10.1002/mnfr.200900609. [PubMed: 20540147]

37. Joshi DV, Patil RR, Naik SR. Hydroalcohol extract of Trigonella foenum-graecum seed attenuates markers of inflammation and oxidative stress while improving exocrine function in diabetic rats. Pharm Biol. 2015;53(2):201-11. doi: 10.3109/13880209.2014.913296. [PubMed: 25339548]

38. Ryan AS, Nicklas BJ. Reductions in plasma cytokine levels with weight loss improve insulin sensitivity in overweight and obese postmenopausal women. Diabetes Care. 2004;27(7):1699-705. [PubMed: 15220249]

39. Seidel V. Initial and bulk extraction. In: Sarker SD, Latif Z, Gray AI, editors. Natural product isolation. New Jersey: Humana Press; 2006. pp. 27-46.

40. Ciftci ON, Przybylski R, Rudzinska M, Acharya S. Characterization of Fenugreek (Trigonella foenum-graecum) Seed Lipids. Journal of the American Oil Chemists' Society. 2011;88(10):1603-10. 